\title{
Avaliação do comportamento de estanqueidade à água de argamassas e hidrorrepelentes - Parte II
}

\section{Behavior evaluation of watertight of mortars and water repellents - Part II}

\author{
Thiana Dias Herrmann ${ }^{1}$, Gihad Mohamad ${ }^{1}$, \\ Rogério Cattelan Antocheves de Lima ${ }^{1}$, \\ Almir Barros da Silva Santos Neto ${ }^{1}$, \\ André Lübeck ${ }^{1}$
}

\footnotetext{
${ }^{1}$ Universidade Federal de Santa Maria - UFSM - Avenida Roraima, Centro de Tecnologia, Santa Maria, RS, Brasil. e-mail: thianadh@gmail.com, gihad.civil@gmail.com,rogerio@ufsm.br, almir.neto@ufsm.br, andrelubeck@gmail.com
}

\section{RESUMO}

Além da função estética, os revestimentos de fachada protegem as edificações da penetração de água e, consequentemente, diminuem a propensão ao surgimento de manifestações patológicas que levariam à degradação da superfície. Este trabalho apresenta os ensaios de avaliação do comportamento de estanqueidade à água de revestimentos argamassados, industrializados e dosados em obra, e de revestimentos hidrorrepelentes, formadores de película, destinados a recuperação de fachadas degradadas pela ação da umidade. Para isto, realizaram-se ensaios de permeabilidade ao vapor de água, absorção de água por capilaridade, evaporação, resistência à tração na flexão e resistência à compressão. Ao término do programa experimental, constatou-se que os revestimentos hidrorrepelentes são mais indicados para proteção à ação da água, pois apresentaram melhores resultados quanto à estanqueidade à água do que os revestimentos argamassados, considerando as propriedades avaliadas.

Palavras-chave: Estanqueidade à água. Recuperação de fachadas. Umidade.

\section{ABSTRACT}

Beyond the aesthetic function, the facade coatings protect buildings from water penetration and, consequently, diminishes the propensity for pathological manifestations that lead to their degradation of the surface. This work presents the tests to evaluate the watertight behavior of mortar, industrialized and mixed in construction, and water repellent coatings, film formers, destined the facades degraded by the action of humidity. For this, water vapor permeability, water absorption by capillarity, evaporation, flexural tensile strength and tensile strength in flexion and compression, were performed. At the end of the experimental program, it was found that water repellent coatings are better suited to protect from the action of water, since they presented better results to the watertightness test than the mortar coatings, considering the evaluated properties.

Keywords: Watertightness. Recovery of façades. Humidity.

\section{INTRODUÇÃO}

Qualquer elemento de construção sofre um processo natural de degradação, podendo ser acelerado ou retardado de acordo com suas condições de exposição, sua própria sensibilidade à degradação e, também, pelas intervenções de manutenção, sejam preventivas ou corretivas. Segundo a norma brasileira NBR 15575-1 [1], a exposição dos materiais à água, seja proveniente da chuva, do solo ou do próprio uso da edificação, precisa ser considerada no projeto, pois a umidade acelera os mecanismos de deterioração e ocasiona perda das condições de habitabilidade e de higiene do edifício. Deste modo, um dos requisitos da edificação, é garantir a estanqueidade do sistema às fontes de umidade.

A presença de água, de acordo com Palha et al. [2], é uma das causas mais recorrentes de defeitos em construções. É um fator relevante para a escolha dos materiais que irão compor os locais propensos à umidade. No caso de materiais de fachadas, é importante a correta escolha, pois estas estarão diretamente expostas 
à ação climática [3]. O modo como um revestimento reage à umidade é um indício primordial em termos de desempenho quanto à estanqueidade [4].

As construções são submetidas a períodos de molhagem e secagem em função das mudanças climáticas no ambiente, o que torna essencial as medições do transporte de vapor e água líquida nos materiais para o entendimento da degradação e restauração [5]. Conforme Delgado et al. [6], os mecanismos que abrangem o transporte de água nos elementos e componentes de construção são muito complexos, pois estes estão expostos a variações de temperatura, umidade relativa, precipitação, pressão do vento e radiação solar e, ainda, pela própria estrutura porosa dos materiais.

O transporte de água em um material é possível a partir da existência de uma rede de poros (ou poros capilares) que possibilitam a transferência de umidade internamente. Em materiais compostos por cimento Portland, a água está presente desde sua produção, passando pelo processo de hidratação, onde parte da água forma o gel e parte, em excesso, evapora criando a rede de poros capilares. Deste modo, o transporte da água nestes poros ocorre na forma líquida ou de vapor [7]. Assim, é importante a compreensão de como a água se movimenta na estrutura de um material poroso, pois caso ela se mova em sua fase líquida, poderá transportar substâncias deletérias, e caso se mova na fase de vapor, poderá ficar retida nos poros pela higroscopicidade [8].

A umidade transportada por um material ocorre em diversas fases: fixação, transporte e secagem. Na fase de fixação a umidade pode se fixar nos poros por adsorção física e condensação. A adsorção é um fenômeno físico que acontece quando uma quantidade de água se fixa no poro de em um material sem que haja interação química [9]. E a condensação capilar ocorre quando em qualquer ponto no interior de um material a pressão de vapor deve ser menor ou igual à pressão de saturação, assim, o transporte de água passa da fase de vapor para a fase líquida [10].

A umidade pode estar presente nos materiais porosos nas formas de vapor, líquida ou sólida, e se transporta nos materiais de construção através da permeabilidade, que é a propriedade que caracteriza a facilidade com que um fluído se desloca sob a ação de uma diferença de pressão [11]. A água é transferida no interior do meio poroso, principalmente, na fase líquida pelo fenômeno de capilaridade, e na fase de vapor pelo fenômeno de difusão. A capilaridade, conforme Yang et al. [12], consiste no fluxo insaturado conduzido por forças capilares. A água flui internamente em um material poroso sob a ação de uma força capilar, função da estrutura dos poros do material e do teor de água local. A velocidade do fluxo do líquido produzido pela força capilar depende da estrutura dos poros e do teor de água [13]. Já a difusão de vapor é o processo em que a matéria é transportada de uma parte de um sistema para outro, em função de um gradiente de concentração, onde o vapor se transporta devido a existência de uma diferença de pressão entre as duas regiões, da região de maior para a de menor pressão [11,14].

A secagem é a transferência de um líquido presente nos poros de um material sólido para o ar circundante, podendo ser representada por meio de uma curva de secagem que apresenta a perda de umidade ao longo do tempo [15]. Observa-se nas curvas de secagem três fases distintas. Inicialmente, a secagem acontece a uma taxa constante e o teor de umidade diminui linearmente, contudo se mantém uniforme ao longo da espessura do material. A segunda, quando o líquido não mais atingir a superfície do material e o teor de água alcançar o ponto crítico, a evaporação na superfície diminui e a frente de secagem regressa para o interior do material. A terceira, quando a taxa de secagem vai diminuindo até atingir o equilíbrio higroscópico entre o meio ambiente e o material, mas só se consegue a secagem total quando utilizam-se métodos de secagem artificial [16].

Argamassas com maior porosidade aberta propiciam maior absorção de água, maior permeabilidade ao vapor de água e menor resistência à difusão de vapor de água, e facilitam o processo de secagem $[17,18]$. A rugosidade e a camada de acabamento influenciam também no processo de secagem, quando há um acabamento pintado, se reduz a taxa de evaporação [19].

O diagnóstico da movimentação da umidade em materiais e elementos de construção é essencial para o seu comportamento, afetando, também, sua durabilidade, impermeabilização, degradação e isolamento térmico [6]. De fato, é importante minimizar os efeitos da umidade na conservação das edificações, uma vez que esta é uma das principais causas da degradação dos materiais porosos de construção. Portanto, este trabalho tem como objetivo avaliar, em laboratório, o comportamento frente a estanqueidade à água de revestimentos argamassados e revestimentos hidrorrepelentes para a utilização em fachadas degradadas pela ação da umidade. 


\section{MATERIAIS E MÉTODOS}

Os revestimentos avaliados, quanto à estanqueidade à água, encontram-se apresentados no Quadro 1, sendo os revestimentos argamassados classificados como materiais cimentícios para impermeabilização, segundo a NBR 9575 [20], e os revestimentos hidrorrepelentes, como membrana para impermeabilização, segundo a mesma norma. O revestimento argamassado AP-IND-RM, que não possui ação hidrofugante, foi utilizado como referência comparativa em relação ao desempenho dos demais revestimentos.

Tabela 1: Revestimentos de argamassas e hidrorrepelentes utilizados na pesquisa.

\begin{tabular}{|c|c|c|c|c|}
\hline \multirow{8}{*}{ ARGAMASSA } & \multirow{2}{*}{$\begin{array}{l}\text { Argamassa } \\
\text { dosada em obra }\end{array}$} & Revestimento com aditivo líquido & AP-DO-L & \multirow{5}{*}{ 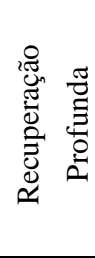 } \\
\hline & & Revestimento com aditivo em pó & AP-DO-P & \\
\hline & \multirow{6}{*}{$\begin{array}{l}\text { Argamassa } \\
\text { industrializada }\end{array}$} & Revestimento reboco médio (referência) & AP-IND-RM & \\
\hline & & Revestimento com aditivo impermeabilizante & AP-IND-I1 & \\
\hline & & Revestimento com aditivo impermeabilizante & AP-IND-I2 & \\
\hline & & Colante piso sobre piso & AS-PSP & \multirow{7}{*}{ 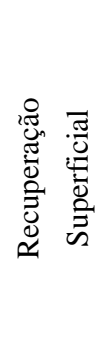 } \\
\hline & & Colante ACIII & AS-ACIII & \\
\hline & & Polimérica bicomponente & AS-PB & \\
\hline \multirow{4}{*}{ HIDRORREPELENTE } & \multirow{4}{*}{\multicolumn{2}{|c|}{ Formador de película }} & HIDRO1 & \\
\hline & & & HIDRO2 & \\
\hline & & & HIDRO3 & \\
\hline & & & HIDRO4 & \\
\hline
\end{tabular}

\subsection{Permeabilidade ao vapor de água}

Este ensaio mede a transmissão de vapor de água em argamassas em seu estado endurecido, quando são submetidas a um ambiente com diferenças de pressão de vapor entre suas superfícies, em condições de temperatura e umidade relativa do ar constantes.

Os procedimentos de ensaio seguiram a norma EN 1015-19 [21], onde utilizaram-se cinco corpos de prova de $150 \mathrm{~mm}$ de diâmetro e $20 \mathrm{~mm}$ de altura para cada revestimento, com cura de 28 dias em ambiente de laboratório com temperatura ambiente de $23 \pm 2{ }^{\circ} \mathrm{C}$ e umidade relativa do ar de $60 \pm 5^{\circ} \mathrm{C}$. Após a cura, montaramse os copos testes seguindo as recomendações da norma, que foram colocados em uma câmara climática com uma umidade relativa de $95 \pm 5 \%$ e temperatura de $20 \pm 2^{\circ} \mathrm{C}$. Para os revestimentos utilizados como recuperação superficial, utilizaram-se corpos de prova da argamassa referência industrializa (AP-IND-RM), nos quais se aplicou superficialmente o revestimento. Para permitir o fluxo de vapor, foi utilizada a solução salina saturada de cloreto de lítio $(\mathrm{LiCl})$, a qual fornece uma umidade relativa de $12,4 \%$ a uma temperatura de $20{ }^{\circ} \mathrm{C}$. As pesagens dos copos testes foi diária durante 15 dias.

Anteriormente a montagem dos copos teste, os corpos de prova foram vedados com silicone nas bordas que estão fora do limite do diâmetro interno do copo, onde se encontra a solução salina, nas faces inferior e superior. Colocou-se a solução salina no diâmetro interno do copo, deixando uma camada de ar de $10 \pm 5 \mathrm{~mm}$. Fixou-se uma fita de massa de calafetar na borda do diâmetro interno do copo, vedando o contato do copo com a amostra. O corpo de prova foi colocado no copo teste sobre a massa de calafetar, aplicando-se uma leve pressão. Fixou-se fita de massa de calafetar na borda externa do copo, vedando o corpo de prova em relação ao ambiente externo. Estas etapas estão ilustradas na Figura 1. 


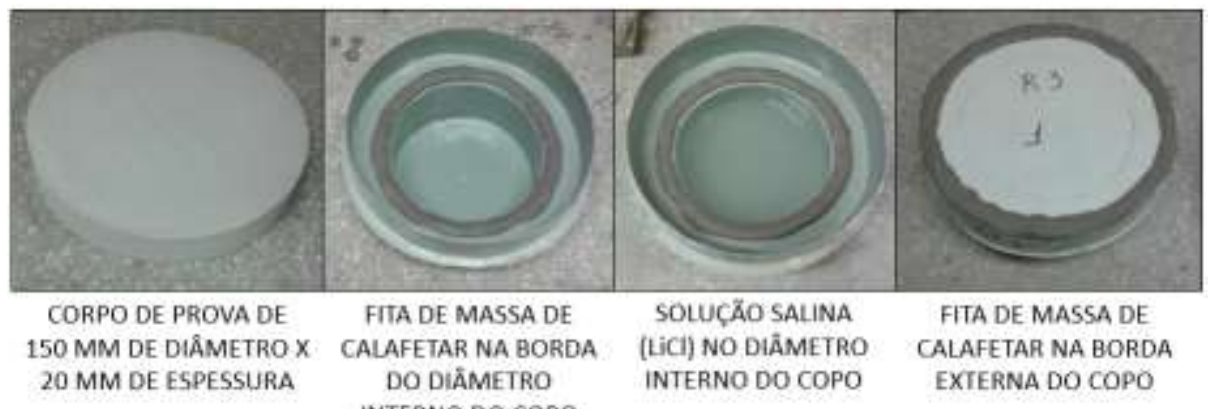

Figura 1: Etapas da montagem dos copos teste.

Com este ensaio é possível elaborar um gráfico demonstrando o ganho ou a perda de massa da amostra ao longo do tempo e, também, calcular a permeância ao vapor de água $(\Lambda)$, conforme a equação proposta pela norma EN 1015-19 [21], podendo-se, em seguida, determinar a permeabilidade ao vapor de água ( $\pi$ ) que é o resultado da permeância $(\Lambda)$ multiplicada pela espessura do corpo de prova. Também, pode-se determinar o coeficiente de permeabilidade ao vapor de água ( $\mu$ ), de acordo com a norma EN 998-1 [22].

\subsection{Absorção de água por capilaridade}

O ensaio de absorção de água por capilaridade foi realizado conforme as especificações da norma NBR 9779 [23], que determina a absorção de água por ascensão capilar. Foram utilizados 3 corpos de prova para cada revestimento, com dimensões de $4 \mathrm{~cm} \times 4 \mathrm{~cm} \times 16 \mathrm{~cm}$, curados em temperatura ambiente de $23 \pm 2{ }^{\circ} \mathrm{C}$ e umidade relativa do ar de $60 \pm 5^{\circ} \mathrm{C}$ até a idade de 28 dias. Após a cura, as amostras foram imersas em um recipiente sobre uma lâmina de água de $5 \pm 1 \mathrm{~mm}$ de altura, em um ambiente com temperatura constante de $23 \pm 2{ }^{\circ} \mathrm{C}$. A determinação da massa saturada foi realizada a partir das pesagens dos corpos de prova em $3 \mathrm{~h}$, $6 \mathrm{~h}, 24 \mathrm{~h}, 48 \mathrm{~h}$ e $72 \mathrm{~h}$.

Para os revestimentos utilizados como recuperação superficial, utilizaram-se corpos de prova da argamassa referência industrializada (AP-IND-RM), aplicando o revestimento superficial na face inferior e nas faces laterais da amostra. Os resultados foram calculados de acordo a equação apresentada pela NBR 9779 [23].

\subsection{Evaporação}

O ensaio de evaporação foi baseado nos estudos de Brito [24], que utilizou o método da norma RILEM N ${ }^{0}$ II 5. Este ensaio determina o tempo necessário para um corpo de prova de argamassa perder água por evaporação, após ter sido submetido à imersão em água.

Utilizaram-se três corpos de prova com dimensões de $4 \mathrm{~cm} \times 4 \mathrm{~cm} \times 16 \mathrm{~cm}$ para cada revestimento, curados durante 28 dias em condições de laboratório com temperatura ambiente de $23 \pm 2{ }^{\circ} \mathrm{C}$ e umidade relativa do ar de $60 \pm 5^{\circ} \mathrm{C}$, sendo após submetidos a secagem em estufa a uma temperatura de $60{ }^{\circ} \mathrm{C}$ até atingirem constância de massa entre duas pesagens consecutivas. As quatro faces laterais do corpo de prova foram seladas com duas demãos de resina epóxi e a face inferior foi colocada sobre uma lâmina d'água de altura constante de $5 \mathrm{~mm}$ durante 96 horas. Após este período, os corpos de prova foram retirados da água e sua face inferior foi selada com uma folha plástica de polietileno. Deste modo, permitiu-se a evaporação da água apenas através da face superior das amostras (unilateralmente). Para os revestimentos de recuperação superficial, utilizaram-se corpos de prova da argamassa referência industrializada (AP-IND-RM), que tiveram as quatro faces laterais seladas com resina epóxi e a face superior revestida pelos diferentes revestimentos. A Figura 2 ilustra cada etapa do ensaio. 


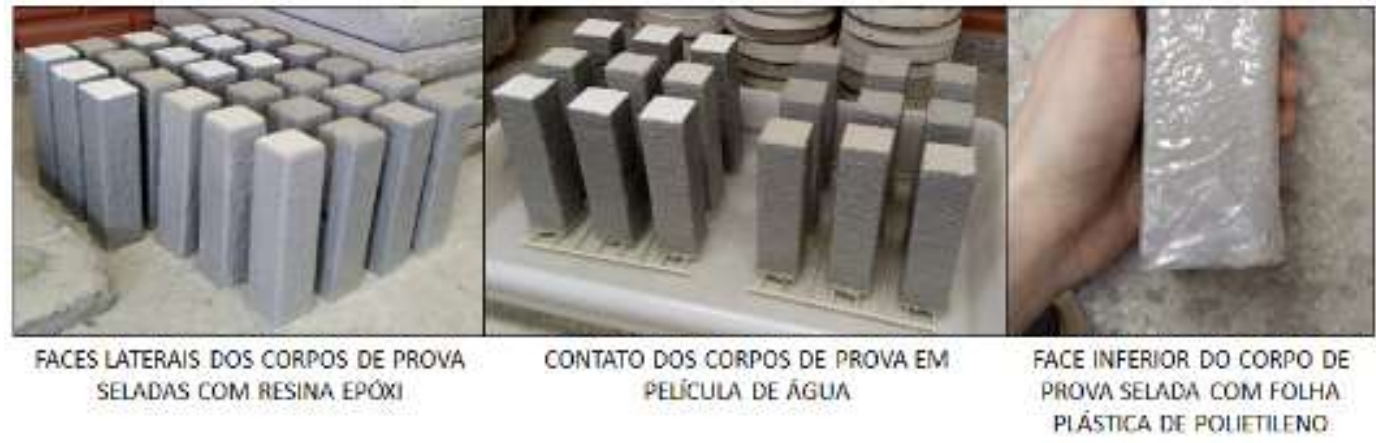

Figura 2: Etapas do ensaio de evaporação.

As pesagens das amostras foram realizadas após a secagem em estufa antes e após a imersão em água, em intervalos de $1 \mathrm{~h}$ durante $7 \mathrm{~h}$, a partir de quando se iniciou o ensaio de evaporação (após imersão). Em seguida, a pesagem ocorreu diariamente durante 7 dias, em seguida três vezes por semana durante 10 semanas e, após, as pesagens foram efetuadas uma vez por semana. O tempo total do ensaio de evaporação foi de 252 dias. O resultado pode ser expresso pela curva de evaporação relacionando o teor de água evaporada com a variação do tempo, onde o teor de água é obtido conforme a Equação 1.

$$
\mathrm{W}_{\mathrm{i}}=\frac{\mathrm{m}_{\mathrm{i}}-\mathrm{m}_{\text {seca }}}{\mathrm{m}_{\text {seca }}} \times 100
$$

Onde, $\mathrm{W}_{\mathrm{i}}=$ teor de água evaporada $(\%) ; \mathrm{m}_{\mathrm{i}}=$ massa do corpo de prova no instante $\mathrm{ti}(\mathrm{g}) ; \mathrm{m}_{\text {seca }}=$ massa do corpo de prova seco em estufa $(\mathrm{g})$.

\subsection{Resistência à tração na flexão e à compressão}

Este ensaio foi executado conforme a norma NBR 13279 [25]. Foram confeccionados três corpos de prova com dimensões de $4 \times 4 \times 16 \mathrm{~cm}$, curados durante 28 dias em ambiente de laboratório com temperatura ambiente de $23 \pm 2{ }^{\circ} \mathrm{C}$ e umidade relativa do ar de $60 \pm 5^{\circ} \mathrm{C}$, apenas para os revestimentos de argamassa de recuperação profunda. Primeiramente, foram rompidos à tração na flexão e após à compressão. Os cálculos das resistências à tração na flexão e à compressão foram realizados conforme as equações apresentadas pela norma.

\section{RESULTADOS E DISCUSSÕES}

\subsection{Permeabilidade ao vapor de água}

\subsubsection{Revestimentos Argamassados}

Na Figura 3, apresenta-se os resultados de permeabilidade ao vapor de água das argamassas de recuperação profunda, as quais obtiveram ganho de massa constante durante os 15 dias de ensaio. A argamassa dosada em obra AP-DO-P permitiu a maior passagem de fluxo de vapor através dos corpos de prova, dentre todas as argamassas de recuperação profunda. Já a argamassa dosada em obra AP-DO-L obteve a menor permeabilidade ao vapor d'água e as argamassas industrializadas exibiram um ganho de massa intermediário. Todas as argamassas, com exceção de AP-DO-P, apresentaram menor permeabilidade em relação à argamassa referência AP-IND-RM. 


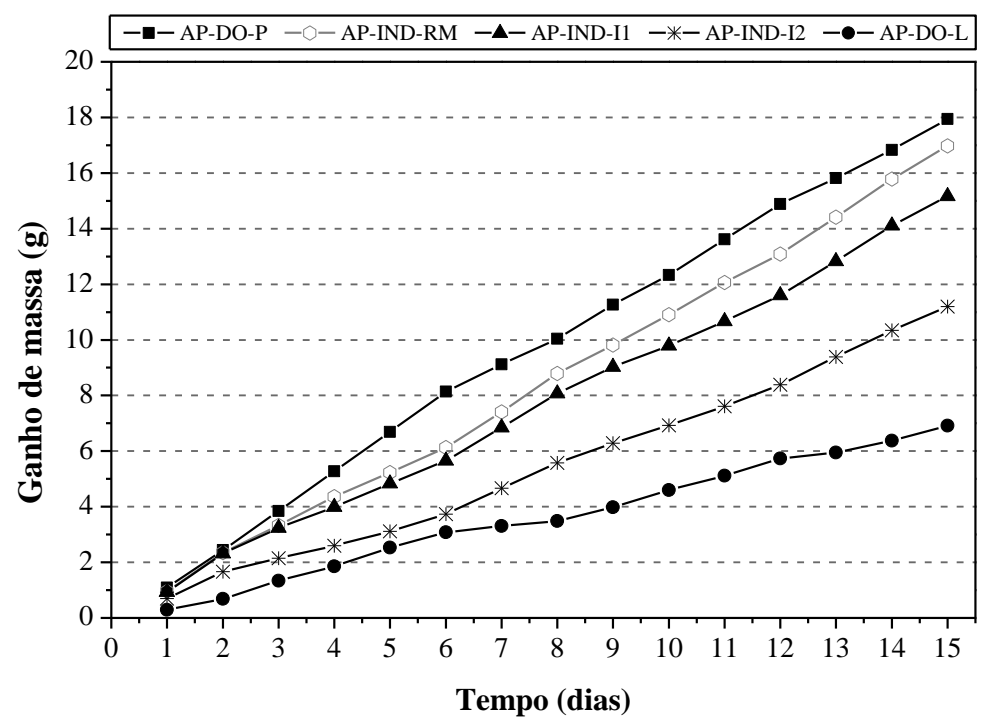

Figura 3: Ganho de massa diário das argamassas de recuperação profunda.

Na Tabela 2, expõe-se as características das argamassas de recuperação profunda, possibilitando uma melhor avaliação do seu desempenho. Percebe-se que o revestimento AP-IND-I1 e a referência AP-IND-RM obtiveram um fluxo de vapor através das amostras muito semelhante, bem como, o revestimento AP-INDRM apresentou desempenho à permeabilidade ao vapor próximo a do revestimento AP-DO-P. Ainda, o revestimento menos permeável AP-DO-L atingiu um resultado discrepante das demais argamassas, sendo $59,31 \%$ menos permeável do que a argamassa referência AP-IND-RM.

Tabela 2: Características das argamassas de recuperação profunda.

\begin{tabular}{l|c|c|c|c|c}
\hline REVESTIMENTO & $\begin{array}{c}\text { GANHO } \\
\text { DE MASSA } \\
\mathbf{( g )}\end{array}$ & $\begin{array}{c}\text { PERMEÂNCIA } \\
\boldsymbol{\Lambda}\left(\mathbf{k g} / \mathbf{m}^{2} \mathbf{. s . P a}\right)\end{array}$ & $\begin{array}{c}\text { PERMEABILIDADE } \\
\boldsymbol{\pi} \mathbf{( n g / m . s . P a )}\end{array}$ & $\begin{array}{c}\text { COEFICIENTE DE } \\
\text { PERMEABILIDADE } \\
\boldsymbol{\mu}\end{array}$ & $\begin{array}{c}\text { \% DE GANHO DE } \\
\text { MASSA EM RELA- } \\
\text { ÇÃO À AP-IND-RM }\end{array}$ \\
\hline AP-DO-L & 6,91 & $3,58 \mathrm{E}-10$ & 7,16 & 0,54 & $-59,31$ \\
\hline AP-IND-I2 & 11,2 & $5,86 \mathrm{E}-10$ & 11,73 & 0,33 & $-34,04$ \\
\hline AP-IND-I1 & 15,17 & $8,02 \mathrm{E}-10$ & 16,04 & 0,24 & $-10,66$ \\
\hline AP-IND-RM & 16,98 & $9,02 \mathrm{E}-10$ & 18,04 & 0,22 & - \\
\hline AP-DO-P & 17,94 & $9,55 \mathrm{E}-10$ & 19,11 & 0,20 & 5,65 \\
\hline
\end{tabular}

Na Figura 4 demonstram-se os resultados de permeabilidade ao vapor de água para os revestimentos de argamassa de recuperação superficial. Observa-se que o fluxo de vapor nestas argamassas é similar, onde as argamassas colantes resultaram permeabilidades muito próximas, seguidas da argamassa polimérica bicomponente. Com a aplicação destes revestimentos na face externa do corpo de prova da argamassa referência AP-IND-RM, houve um bloqueio no fluxo de vapor. 


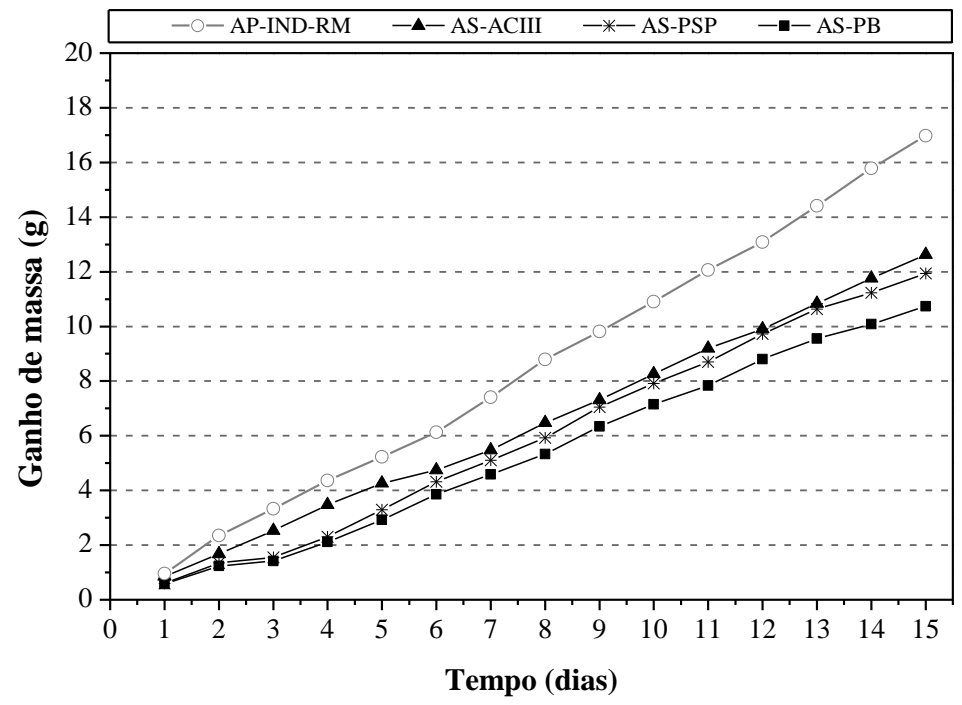

Figura 4: Ganho de massa diária das argamassas de recuperação superficial.

A partir da Tabela 3, analisam-se as características para a permeabilidade ao vapor de água das argamassas de recuperação superficial. Do mesmo modo, visualiza-se a semelhança do comportamento entre estas argamassas, sendo em torno de 25 a $36 \%$ menos permeáveis ao vapor de água do que a argamassa referência AP-IND-RM.

Tabela 3: Características das argamassas de recuperação superficial.

\begin{tabular}{l|c|c|c|c|c}
\hline REVESTIMENTO & $\begin{array}{c}\text { GANHO DE } \\
\text { MASSA } \mathbf{( g )}\end{array}$ & $\begin{array}{c}\text { PERMEÂNCIA } \\
\boldsymbol{\Lambda}\left(\mathbf{k g} / \mathbf{m}^{2} . \mathbf{s} . P a\right)\end{array}$ & $\begin{array}{c}\text { PERMEABILIDADE } \\
\boldsymbol{\pi} \mathbf{( n g / m . s . P a )}\end{array}$ & $\begin{array}{c}\text { COEFICIENTE DE } \\
\text { PERMEABILIDADE } \boldsymbol{\mu}\end{array}$ & $\begin{array}{c}\text { \% DE GANHO DE } \\
\text { MASSA EM RELA- } \\
\text { ÇÃO À AP-IND-RM }\end{array}$ \\
\hline AS-PB & 10,74 & $5,62 \mathrm{E}-10$ & 11,23 & 0,35 & $-36,75$ \\
\hline AS-PSP & 11,94 & $6,26 \mathrm{E}-10$ & 12,52 & 0,31 & $-29,68$ \\
\hline AS-ACIII & 12,63 & $6,64 \mathrm{E}-10$ & 13,27 & 0,29 & $-25,62$ \\
\hline AP-IND-RM & 16,98 & $9,02 \mathrm{E}-10$ & 18,04 & 0,22 & - \\
\hline
\end{tabular}

Diante disso, a permeabilidade ao vapor de água para os revestimentos de argamassa de recuperação profunda e superficial foi inferior ao da argamassa referência AP-IND-RM, com exceção da argamassa APDO-P. Este comportamento já era esperado, pois ao se adicionar componentes impermeabilizantes às argamassas, há o tamponamento dos poros e, por consequência, redução da passagem do vapor pela amostra.

$\mathrm{Na}$ Tabela 4 apresentam-se os resultados de outros autores obtidos para o ensaio de permeabilidade ao vapor de água em argamassas. Como este trabalho utilizou revestimentos comerciais do mercado da construção civil, não foram encontrados autores que apresentassem resultados para revestimentos semelhantes aos utilizados. Nos resultados da Tabela 3, o que mais se aproximou deste trabalho foi de Jantsch [27], com permeabilidade atingindo $20 \mathrm{ng} / \mathrm{m}$.s.Pa.

Tabela 4: Resultados do ensaio de permeabilidade ao vapor de água de diferentes autores.

\begin{tabular}{c|c|c|c}
\hline \multirow{2}{*}{ AUTOR } & TIPO DE REVESTIMENTO DE ARGAMASSA & $\begin{array}{c}\text { PERMEABILIDADE } \\
(\mathbf{n g} / \mathbf{m . s . P a})\end{array}$ & $\begin{array}{c}\text { SOLUÇÃO SALINA } \\
\text { UTILIZADA }\end{array}$ \\
\hline \multirow{3}{*}{ Temp [26] } & Argamassa de alta porosidade & 7,00 & $\mathrm{NiCl}$ \\
\cline { 2 - 4 } & Argamassa estabilizada de 36h & 9,00 & $\mathrm{NiCl}$ \\
\cline { 2 - 4 } & Argamassa de reboco médio & 9,00 & $\mathrm{NiCl}$ \\
\hline \multirow{2}{*}{ Jantsch [27] } & Argamassa estabilizada de 36h & $17,01-20,95$ & $\mathrm{KNO}_{3}$ \\
\cline { 2 - 4 } & Argamassa estabilizada de 72h & $13,96-20,09$ & $\mathrm{KNO}_{3}$ \\
\hline \multirow{2}{*}{ Fonseca [28] } & Argamassa cimento:areia & 7,24 & $\mathrm{H}_{2} \mathrm{O}$ \\
\cline { 2 - 4 } & Argamassa cimento:areia: lama ETAR seca & $5,79-9,33$ & $\mathrm{H}_{2} \mathrm{O}$ \\
\hline
\end{tabular}




\begin{tabular}{l|c|c|c}
\hline & Argamassa cimento:areia: lama ETAR calcinada & $5,94-6,13$ & $\mathrm{H}_{2} \mathrm{O}$ \\
\hline Salomão et al. [29] & Argamassa cimento:cal:agregregado & $7-11,6$ & $\mathrm{NiCl}$ \\
\hline
\end{tabular}

\subsubsection{Revestimentos Hidrorrepelentes}

Na Figura 5 exibem-se os resultados de permeabilidade ao vapor de água para os revestimentos hidrorrepelentes, verificando-se um de ganho de massa diário contínuo. A partir da aplicação dos hidrorrepelentes na face externa do corpo de prova da argamassa referência AP-IND-RM, ocorreu a redução do fluxo de vapor passante através da amostra. O revestimento HIDRO4 foi o mais permeável ao vapor de água, seguido dos revestimentos HIDRO3 e HIDRO1. Salienta-se que o revestimento HIDRO2 permitiu a menor passagem de fluxo de vapor.

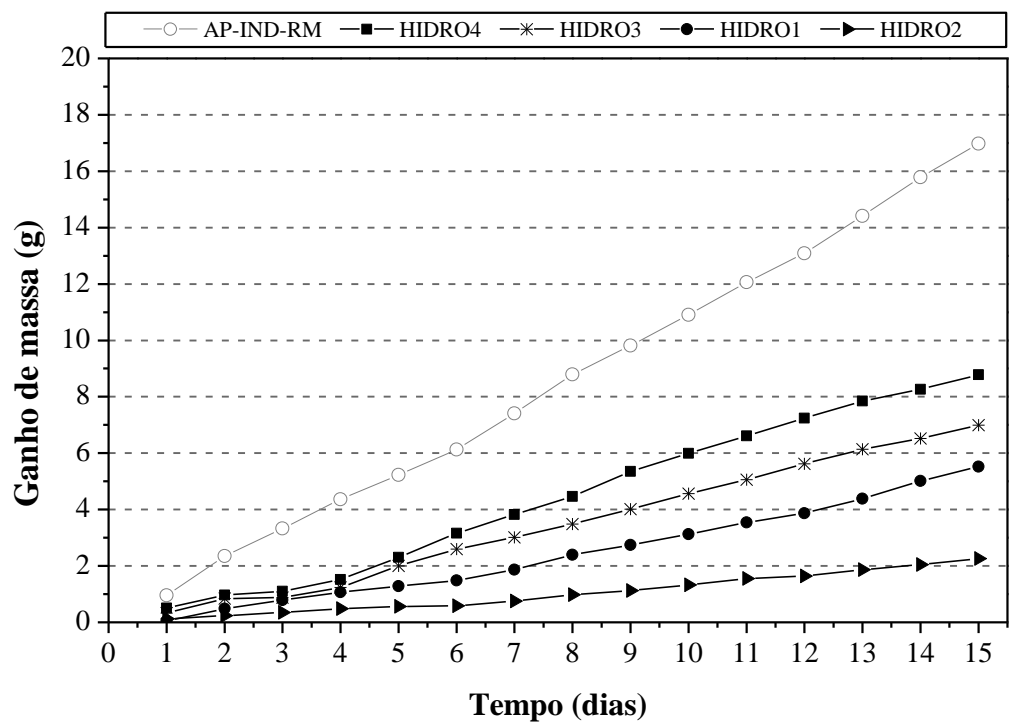

Figura 5: Ganho de massa diário dos hidrorrepelentes.

$\mathrm{Na}$ Tabela 5, apresentam-se os resultados para os revestimentos hidrorrepelentes, visualizando-se que os revestimentos HIDRO2 e HIDRO4 resultaram em valores extremos e opostos. O revestimento HIDRO4 revelou ser em torno de quatro vezes mais permeável do que o revestimento HIDRO2. Os demais revestimentos, HIDRO1 e HIDRO3, apresentaram resultados intermediários, mas também obtiveram permeabilidade ao vapor de água que superam em $100 \%$ o valor do revestimento HIDRO2. Observa-se que a aplicação dos hidrorrepelentes sobre a argamassa referência AP-IND-RM reduziu o fluxo de vapor, onde o revestimento $\mathrm{HIDRO} 2$ bloqueou $86,69 \%$ da difusão do vapor.

Tabela 5: Características dos revestimentos hidrorrepelentes.

\begin{tabular}{l|c|c|c|c|c}
\hline REVESTIMENTO & $\begin{array}{c}\text { GANHO DE } \\
\text { MASSA (g) }\end{array}$ & $\begin{array}{c}\text { PERMEÂNCIA } \\
\boldsymbol{\Lambda}\left(\mathbf{k g} / \mathbf{m}^{2} . \mathbf{s} . P a\right)\end{array}$ & $\begin{array}{c}\text { PERMEABILIDADE } \\
\boldsymbol{\pi}(\mathbf{n g} / \mathbf{m . s . P a})\end{array}$ & $\begin{array}{c}\text { COEFICIENTE DE } \\
\text { PERMEABILIDADE } \boldsymbol{\mu}\end{array}$ & $\begin{array}{c}\text { \% DE GANHO DE } \\
\text { MASSA EM RE- } \\
\text { LAÇÃO À AP-IND- } \\
\text { RM }\end{array}$ \\
\hline HIDRO2 & 2,26 & $1,16 \mathrm{E}-10$ & 2,31 & 1,67 & $-86,69$ \\
\hline HIDRO1 & 5,52 & $2,68 \mathrm{E}-10$ & 5,36 & 0,72 & $-67,49$ \\
\hline HIDRO3 & 6,99 & $3,62 \mathrm{E}-10$ & 7,24 & 0,54 & $-58,83$ \\
\hline HIDRO4 & 8,78 & $4,57 \mathrm{E}-10$ & 9,14 & 0,42 & $-48,29$ \\
\hline AP-IND-RM & 16,98 & $9,02 \mathrm{E}-10$ & 18,04 & 0,22 & - \\
\hline
\end{tabular}




\subsection{Absorção de água por capilaridade}

\subsubsection{Argamassas}

Na Figura 6 apresentam-se os resultados para a absorção de água por capilaridade para as argamassas de recuperação profunda. Percebe-se que todas as argamassas possuem uma absorção inferior à argamassa referência AP-IND-RM. As argamassas industrializadas AP-IND-I1 e AP-IND-I2 resultaram nos menores resultados de absorção capilar, seguidos das argamassas dosadas em obra AP-DO-L e AP-DO-P.

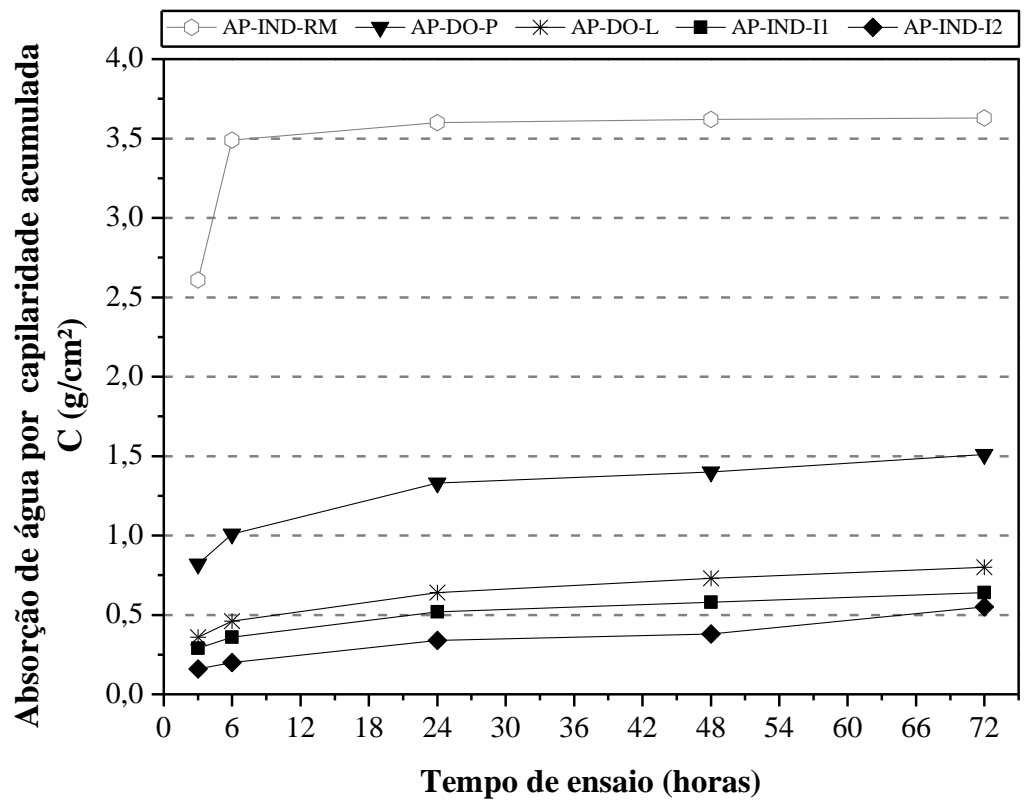

Figura 6: Absorção de água por capilaridade acumulada para as argamassas de recuperação profunda.

$\mathrm{Na}$ Tabela 6 apresentam-se os valores de absorção de água por capilaridade total e o coeficiente de capilaridade das argamassas de recuperação profunda. As argamassas industrializadas AP-IND-I1, AP-INDI2 e AP-DO-L absorveram, em média, 82\% menos água em relação a argamassa de referência AP-IND-RM. Já a argamassa dosada em obra AP-DO-P obteve uma absorção por capilaridade $58,44 \%$ menor que a argamassa referência AP-IND-RM. Quanto maior a absorção, maior é o coeficiente de capilaridade.

Tabela 6: Absorção de água por capilaridade total para as argamassas de recuperação profunda.

\begin{tabular}{l|c|c|c|c|c}
\hline \multicolumn{1}{c|}{ REVESTIMENTO } & AP-IND-I2 & AP-IND-I1 & AP-DO-L & AP-DO-P & AP-IND-RM \\
\hline Absorção de água por capilaridade C total $\left(\mathrm{g} / \mathrm{cm}^{2}\right)$ & 0,55 & 0,64 & 0,80 & 1,51 & 3,63 \\
\hline $\begin{array}{l}\text { Absorção de água por capilaridade em relação ao } \\
\text { referência AP-IND-RM (\%) }\end{array}$ & $-84,79$ & $-82,28$ & $-78,07$ & $-58,44$ & - \\
\hline Coeficiente de capilaridade $\left(\mathrm{g} / \mathrm{dm}^{2} \cdot \mathrm{min}^{1 / 2}\right)$ & 0,36 & 0,42 & 0,52 & 0,99 & 2,38 \\
\hline
\end{tabular}

Os resultados de absorção de água das argamassas de recuperação superficial encontram-se na Figura 7. As argamassas colantes obtiveram absorção capilar inicial muito próxima e, após atingir 6 h de ensaio, a AS-ACIII passou a absorver mais água que AS-PSP até o final do ensaio. A argamassa polimérica bicomponente AS-PB se sobressaiu, pois absorveu menor quantidade de água por capilaridade, permanecendo praticamente estável durante todo o ensaio. Todas as argamassas de recuperação superficial evitaram a ascensão capilar através do corpo de prova da argamassa referência AP-IND-RM. 


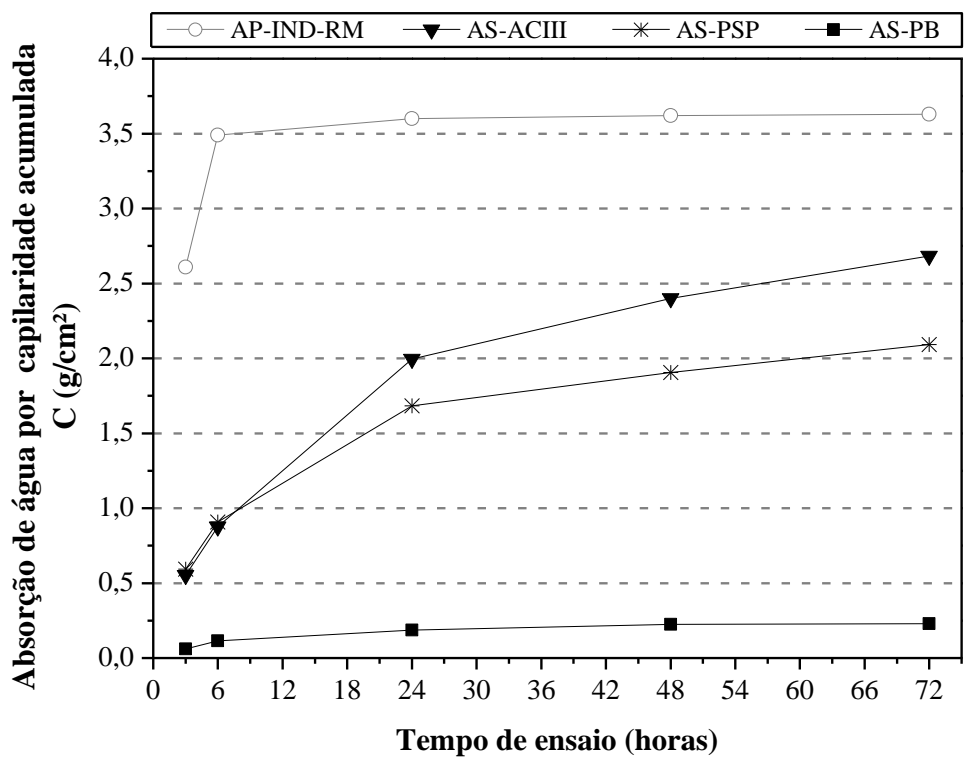

Figura 7: Absorção de água por capilaridade acumulada para as argamassas de recuperação superficial.

Na Tabela 7 apresentam-se as absorções de água por capilaridade total e os coeficientes de capilaridade das argamassas de recuperação superficial. A argamassa AS-PB diminuiu aproximadamente $93 \%$ a absorção capilar da argamassa referência AP-IND-RM, sendo a que mais bloqueou a ascensão capilar entre todas as argamassas avaliadas. Os revestimentos AS-PSP e AS-ACIII diminuíram em torno de $42 \%$ e $26 \%$ a ascensão capilar, respectivamente.

Tabela 7: Absorção de água por capilaridade total para as argamassas de recuperação superficial.

\begin{tabular}{l|c|c|c|c}
\hline \multicolumn{1}{c|}{ REVESTIMENTO } & AS-PB & AS-PSP & AS-ACIII & AP-IND-RM \\
\hline Absorção de água por capilaridade C total $\left(\mathrm{g} / \mathrm{cm}^{2}\right)$ & 0,23 & 2,09 & 2,68 & 3,63 \\
\hline $\begin{array}{l}\text { Absorção de água por capilaridade em relação ao } \\
\text { referência AP-IND-RM }(\%)\end{array}$ & $-93,69$ & $-42,32$ & $-26,06$ & - \\
\hline Coeficiente de capilaridade $\left(\mathrm{g} / \mathrm{dm}^{2} \cdot \mathrm{min}^{1 / 2}\right)$ & 0,15 & 1,38 & 1,76 & 2,38 \\
\hline
\end{tabular}

Na Tabela 8 apresentam-se os resultados de outros autores para o ensaio de absorção de água por capilaridade para argamassas, contudo, como já destacado, os revestimentos avaliados são diferentes aos utilizados neste estudo. Destaca-se Salomão et al. [29] que utilizaram argamassas que absorveram mais água em um intervalo de tempo, chegando a $14,6 \mathrm{~g} / \mathrm{dm}^{2} \cdot \min ^{1 / 2}$. Resultado mais alto em relação aos deste estudo onde o coeficiente de capilaridade variou de 0,15 a 2,38 g/dm². $\mathrm{min}^{1 / 2}$ (Tabela 6), demonstrando baixa absorção.

Tabela 8: Resultados do ensaio de absorção de água por capilaridade de diferentes autores.

\begin{tabular}{c|c|c}
\hline \multirow{2}{*}{ AUTOR } & TIPO DE REVESTIMENTO DE ARGAMASSA & $\begin{array}{c}\text { COEFICIENTE DE } \\
\text { CAPILARIDADE } \mathbf{~} / \mathbf{d m}^{\mathbf{2}} \cdot \mathbf{m i n}^{\mathbf{1} \mathbf{2}}\end{array}$ \\
\hline \multirow{2}{*}{ Jantsch [27] } & Argamassa estabilizada de 36h & 0,5 \\
\cline { 2 - 3 } & Argamassa estabilizada de 72h & $0,3-1,3$ \\
\hline \multirow{3}{*}{ Fonseca [28] } & Argamassa cimento:areia & 3,89 \\
\cline { 2 - 3 } & Argamassa cimento:areia: lama ETAR seca & $0,68-1,51$ \\
\cline { 2 - 3 } & Argamassa cimento:areia: lama ETAR calcinada & $2,32-3,52$ \\
\hline \multirow{2}{*}{ Salomão et al. [29] } & Argamassa cimento:cal:agregregado & $3-14,6$ \\
\hline
\end{tabular}

\subsubsection{Hidrorrepelentes}

Na Figura 8, exibe-se a absorção de água por capilaridade dos revestimentos hidrorrepelentes. Foi destacada 
a parte inicial das medições para facilitar a comparação. Percebe-se que todos impediram consideravelmente o fluxo de água capilar através das amostras da argamassa referência AP-IND-RM. O hidrorrepelente HIDRO2 foi o que mais impediu a absorção capilar, seguido do HIDRO1. Os hidrorrepelentes HIDRO3 e HIDRO4 permitiram uma entrada um pouco maior de água por capilaridade, entretanto, os valores foram ainda pequenos.

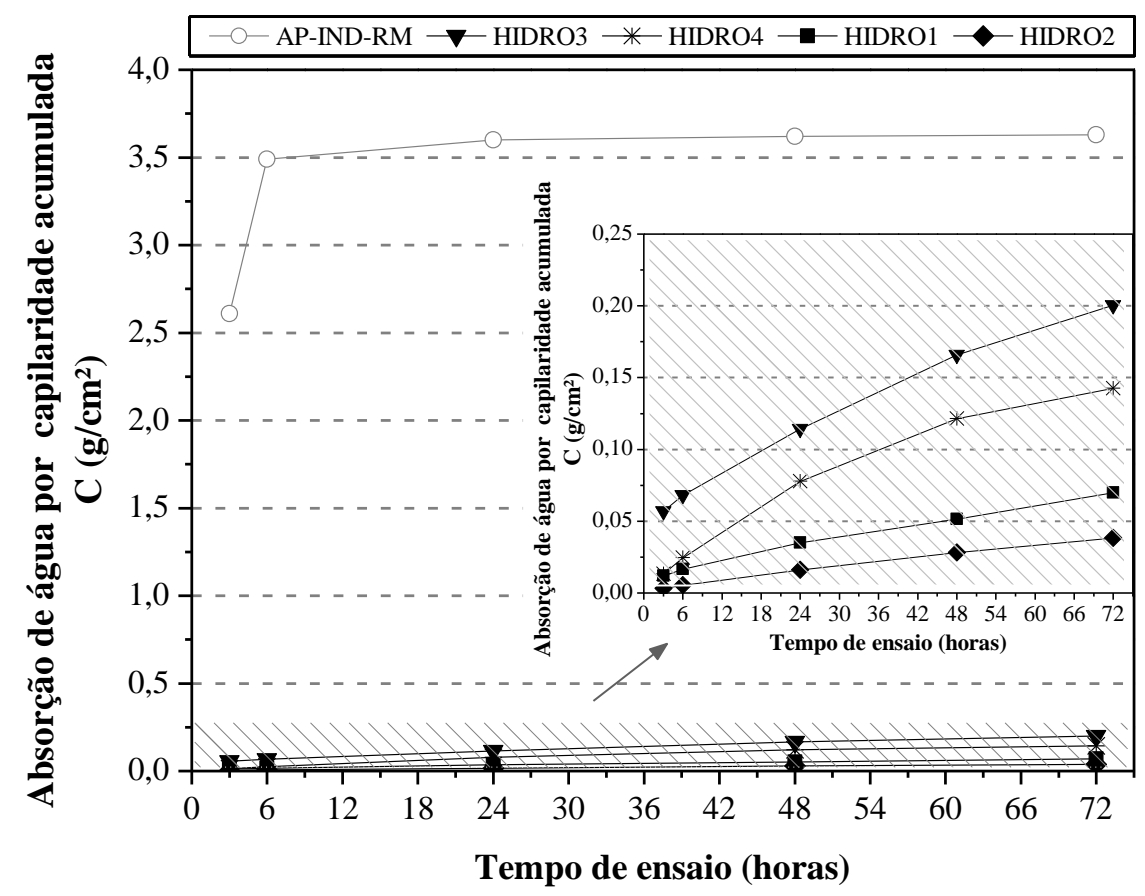

Figura 8: Absorção de água por capilaridade acumulada para os hidrorrepelentes.

A partir dos valores apresentados na Tabela 9, é possível visualizar a redução de absorção de água por capilaridade e o coeficiente de capilaridade dos hidrorrepelentes. O revestimento HIDRO2 reduziu em, praticamente, 99\% a absorção de água pela argamassa referência AP-IND-RM. Isto ocorre também para os demais hidrorrepelentes, os quais diminuíram consideravelmente a absorção de AP-IND-RM.

Tabela 9: Absorção de água por capilaridade total para os hidrorrepelentes.

\begin{tabular}{l|c|c|c|c|c}
\hline \multicolumn{1}{c|}{ REVESTIMENTO } & HIDRO2 & HIDRO1 & HIDRO4 & HIDRO3 & AP-IND-RM \\
\hline Absorção de água por capilaridade C total $\left(\mathrm{g} / \mathrm{cm}^{2}\right)$ & 0,04 & 0,07 & 0,14 & 0,20 & 3,63 \\
\hline $\begin{array}{l}\text { Absorção de água por capilaridade em relação ao } \\
\text { referência AP-IND-RM }(\%)\end{array}$ & $-98,94$ & $-98,07$ & $-96,07$ & $-94,47$ & - \\
\hline Coeficiente de capilaridade $\left(\mathrm{g} / \mathrm{dm}^{2} \cdot \mathrm{min}^{1 / 2}\right)$ & 0,025 & 0,046 & 0,093 & 0,132 & 2,38 \\
\hline
\end{tabular}

\subsection{Evaporação}

\subsubsection{Argamassas}

As curvas de evaporação dos revestimentos de argamassa de recuperação profunda são apresentadas na Figura 9. O tempo de evaporação foi influenciado pela quantidade de água absorvida por capilaridade, sendo maior nas primeiras horas. O revestimento AP-DO-P alcançou a maior difusão de vapor, assim, no ensaio de evaporação, sua capacidade em equilibrar a umidade foi maior. Ao contrário, as argamassas AP-IND-I1 e AP-DO-L tiveram maior dificuldade em expelir a água absorvida. Como a argamassa AP-IND-I2 obteve baixa absorção capilar, rapidamente atingiu o equilíbrio interno, demostrando que a evaporação do teor de água é mais rápida do que nas demais argamassas. A argamassa referência AP-IND-RM apresentou alto teor de água absorvida, então, no encerramento do ensaio ainda não havia atingido o equilíbrio higroscópico, porém, a velocidade de perda de água observada foi alta. 


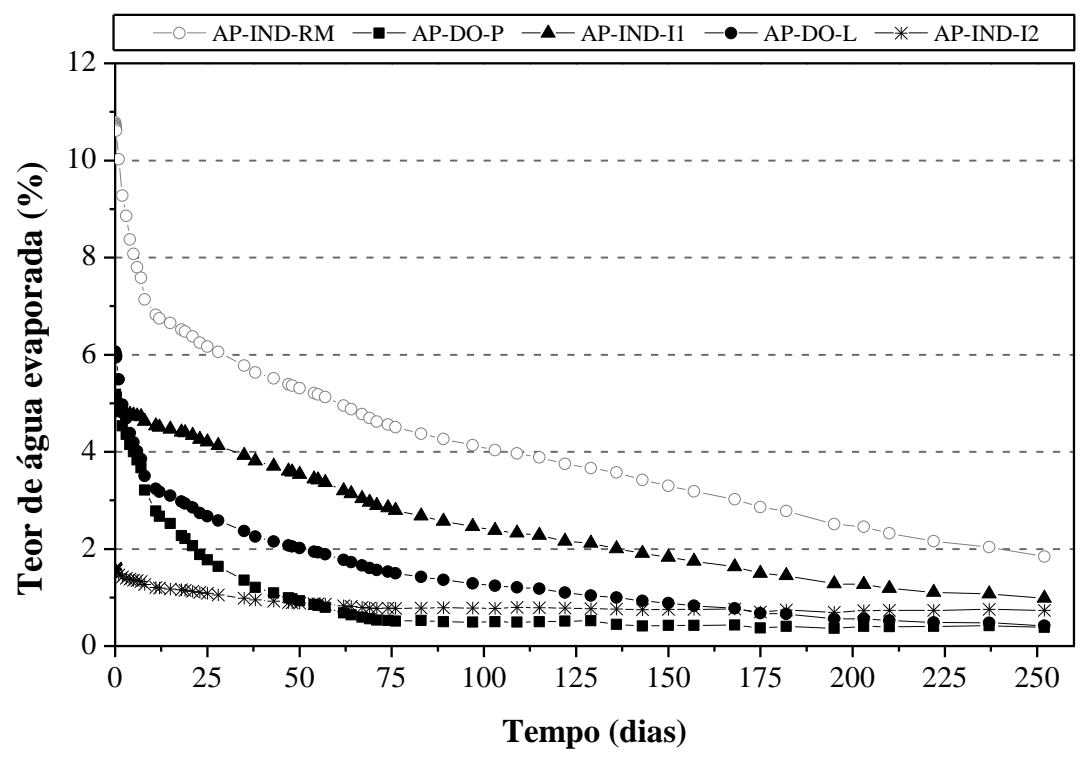

Figura 9: Curva de evaporação das argamassas de recuperação profunda.

Na Tabela 10 apresentam-se os resultados das argamassas de recuperação profunda para o ensaio de evaporação. A diferença dos teores de água de AP-IND-RM iniciou com 10,78\% e finalizou com 1,84\%. O revestimento AP-DO-P atingiu o menor teor de água final, 0,38\%, e o AP-IND-I1 alcançou maior teor inicial $(4,86 \%)$ do que AP-IND-I2 (1,61\%), contudo, chegou a um teor de água final próximo desta.

Tabela 10: Resultados das argamassas de recuperação profunda no ensaio de evaporação.

\begin{tabular}{l|c|c|c|c|c}
\hline REVESTIMENTO & $\begin{array}{c}\text { MASSA } \\
\text { SECA (g) }\end{array}$ & $\begin{array}{c}\text { MASSA } \\
\text { ÚMIDA (g) }\end{array}$ & $\begin{array}{c}\text { QUANTIDADE DE } \\
\text { AUA ABSORVIDA (g) }\end{array}$ & $\begin{array}{c}\text { TEOR DE ÁGUA } \\
\text { INICIAL (\%) }\end{array}$ & $\begin{array}{c}\text { TEOR DE ÁGUA } \\
\text { FINAL (\%) }\end{array}$ \\
\hline AP-IND-RM & 484,00 & 536,19 & 52,19 & 10,78 & 1,84 \\
\hline AP-IND-I1 & 432,83 & 453,86 & 21,03 & 4,86 & 0,98 \\
\hline AP-DO-L & 552,21 & 585,70 & 33,49 & 6,06 & 0,42 \\
\hline AP-DO-P & 495,53 & 521,20 & 25,68 & 5,18 & 0,38 \\
\hline AP-IND-I2 & 512,58 & 520,82 & 8,24 & 1,61 & 0,73 \\
\hline
\end{tabular}

Na Figura 10, apresentam-se as curvas de evaporação para as argamassas de recuperação superficial. Visualiza-se que todas as argamassas reduziram a capacidade de expulsar a água através do corpo de prova da argamassa referência AP-IND-RM. A argamassa AS-PB foi a que mais impediu a saída de água, seguida pelas argamassas AS-PSP e AS-ACIII. Deste modo, estas argamassas aumentariam a possibilidade de ocorrência de manifestações patológicas, uma vez que estariam evitando a saída da água. 


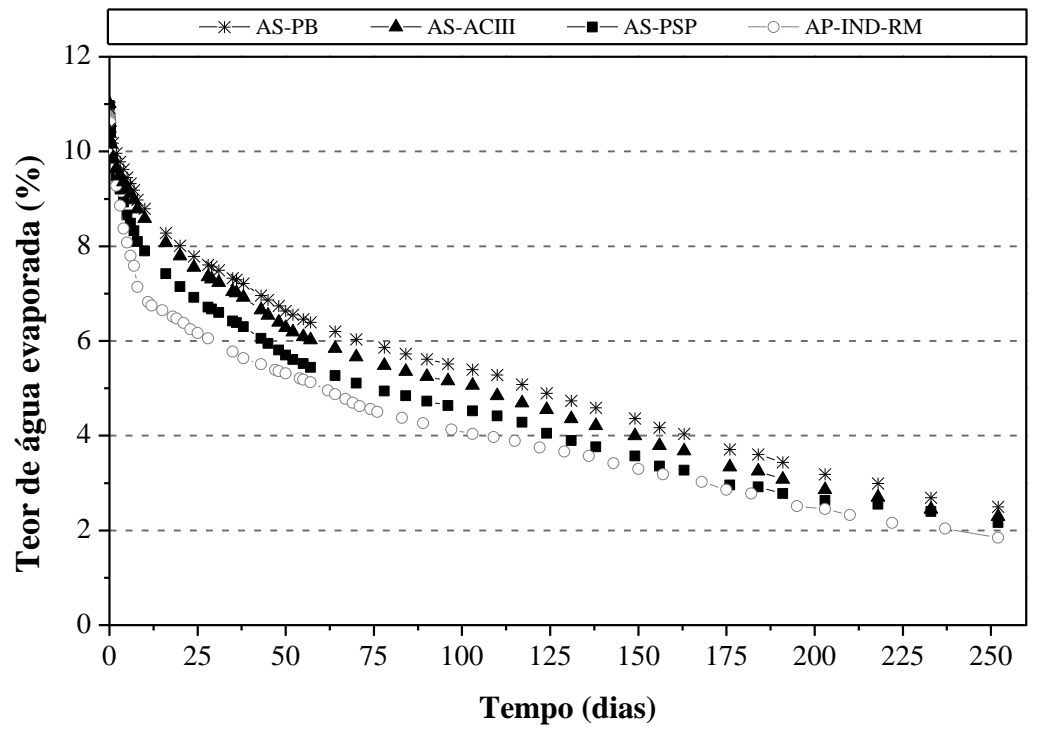

Figura 10: Curva de evaporação das argamassas de recuperação superficial.

Na Tabela 11 estão expostos os resultados das argamassas de recuperação superficial para o ensaio de evaporação. A argamassa de referência AP-IND-RM alcançou um teor de água final de 1,84\%, sendo inferior a todas as argamassas de recuperação, onde AS-PSP atingiu 2,16\%, AS-ACIII, 2,28\% e AS-PB, 2,49\%.

Tabela 11: Resultados do ensaio de evaporação das argamassas de recuperação superficial.

\begin{tabular}{l|c|c|c|c|c}
\hline \multicolumn{1}{|c|}{ REVESTIMENTO } & $\begin{array}{c}\text { MASSA } \\
\text { SECA (g) }\end{array}$ & $\begin{array}{c}\text { MASSA } \\
\text { ÚMIDA (g) }\end{array}$ & $\begin{array}{c}\text { QUANTIDADE DE ÁGUA } \\
\text { ABSORVIDA (g) }\end{array}$ & $\begin{array}{c}\text { TEOR DE ÁGUA } \\
\text { INICIAL (\%) }\end{array}$ & $\begin{array}{c}\text { TEOR DE ÁGUA } \\
\text { FINAL (\%) }\end{array}$ \\
\hline AP-IND-RM & 484,00 & 536,19 & 52,19 & 10,78 & 1,84 \\
\hline AS-PSP & 425,43 & 472,09 & 46,66 & 10,97 & 2,16 \\
\hline AS-ACIII & 428,94 & 476,11 & 47,17 & 11,01 & 2,28 \\
\hline AS-PB & 416,31 & 461,74 & 45,43 & 10,92 & 2,49 \\
\hline
\end{tabular}


Na Figura 11 são apresentadas curvas de evaporação obtidas por diferentes autores. Observa-se que os teores de água inicias são variáveis e que a perda de água ocorre de maneira constante. No trabalho de Faria [31], as curvas são mais acentuadas, atingindo o equilíbrio higroscópico mais rapidamente, com tempo de ensaio em torno de 500 horas (21 dias). Ao contrário, em Martinho [30], o ensaio durou em torno de 1400 horas (58 dias) e, mesmo assim, não alcançou o equilíbrio higroscópico. Os revestimentos utilizados por Fonseca [28] também não atingiram o equilíbrio higroscópico, com tempo de ensaio variando de 50 a 100 horas (2 a 4 dias). Deste modo, percebe-se que para este trabalho, os revestimentos apresentam perda de água (secagem) mais lenta do que as apresentadas pelos autores avaliados.

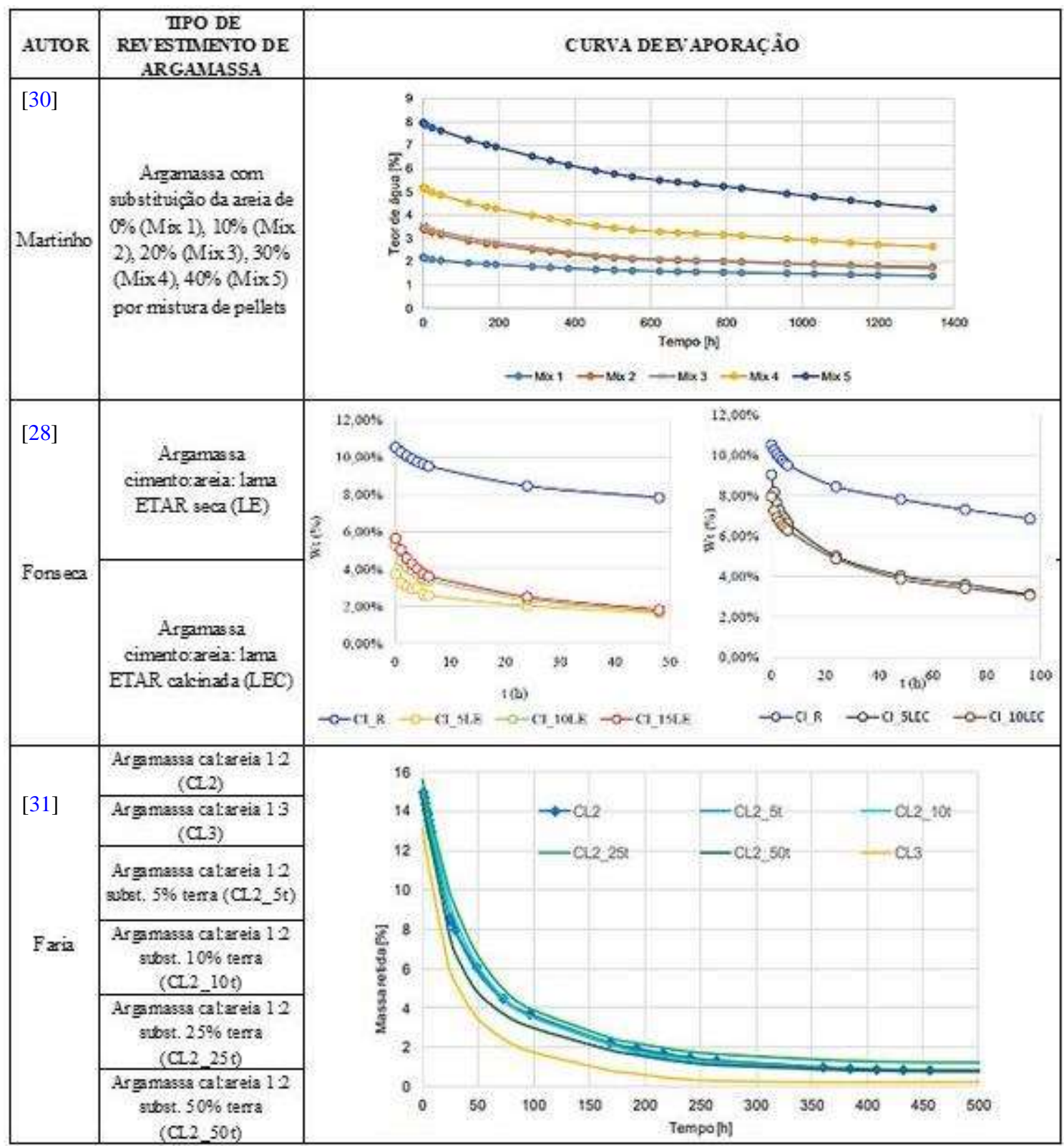

Figura 11: Resultados da curva de secagem do ensaio evaporação de diferentes autores.

\subsubsection{Revestimentos Hidrorrepelentes}

Para os hidrorrepelentes, as curvas de evaporação estão expostas na Figura 12, observando-se que todos os hidrorrepelentes bloquearam a saída da água presente internamente na argamassa referência (AP-IND-RM), principalmente o HIDRO2. Este impedimento de saída da água dos hidrorrepelentes foi maior do que as argamassas, demonstrando que deve haver cuidado quando o revestimento de argamassa estiver saturado de água, pois esta teria o fluxo de saída impedido pelo revestimento externo. 


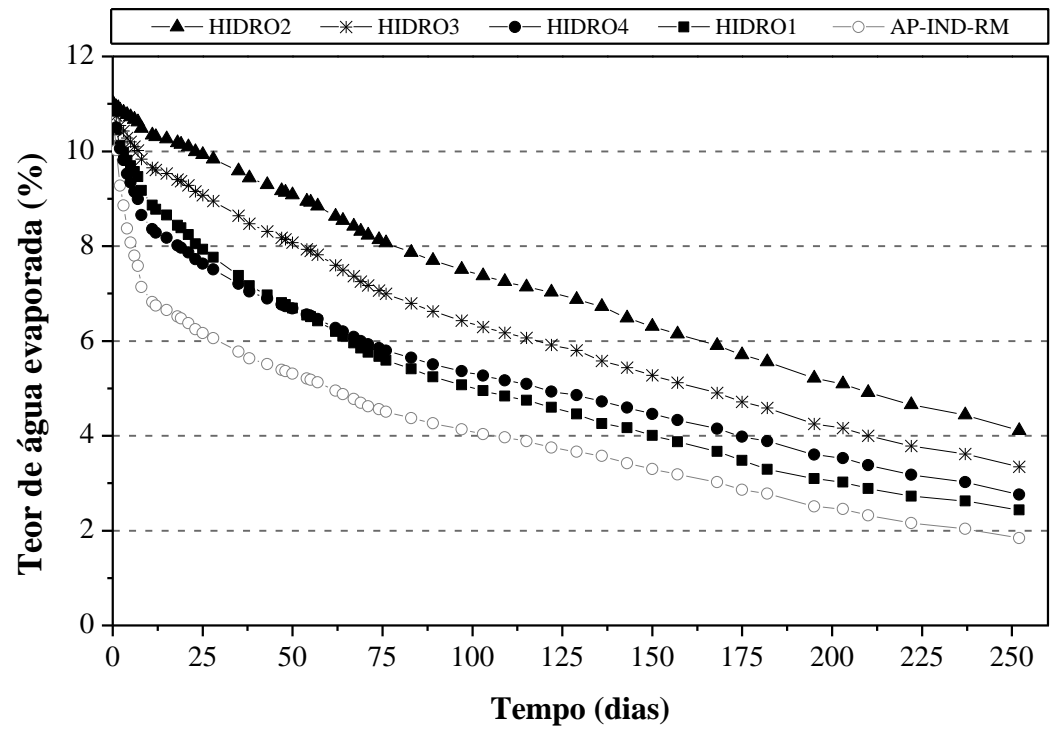

Figura 12: Curva de evaporação dos hidrorrepelentes.

Na Tabela 12, apresentam-se os resultados dos hidrorrepelentes no ensaio de evaporação. Os valores dos teores de água finais revelam o quanto a saída de água foi impedida, sendo que HIDRO2 apresentou um teor de água de $4,11 \%$, mais que o dobro do teor de água final da AP-IND-RM, que foi de 1,84\%.

Tabela 12: Resultados do ensaio de evaporação dos hidrorrepelentes.

\begin{tabular}{l|c|c|c|c|c}
\hline \multicolumn{1}{c|}{ REVESTIMENTO } & $\begin{array}{c}\text { MASSA } \\
\text { SECA (g) }\end{array}$ & $\begin{array}{c}\text { MASSA } \\
\text { ÚMIDA (g) }\end{array}$ & $\begin{array}{c}\text { QUANTIDADE DE ÁGUA } \\
\text { ABSORVIDA (g) }\end{array}$ & $\begin{array}{c}\text { TEOR DE ÁGUA } \\
\text { INICIAL (\%) }\end{array}$ & $\begin{array}{c}\text { TEOR DE ÁGUA } \\
\text { FINAL (\%) }\end{array}$ \\
\hline AP-IND-RM & 484,00 & 536,19 & 52,19 & 10,78 & 1,84 \\
\hline HIDRO1 & 425,33 & 471,63 & 46,30 & 10,89 & 2,44 \\
\hline HIDRO4 & 469,97 & 521,41 & 51,44 & 10,95 & 2,76 \\
\hline HIDRO3 & 435,55 & 483,30 & 47,75 & 10,96 & 3,35 \\
\hline HIDRO2 & 419,73 & 465,92 & 46,19 & 11,01 & 4,11 \\
\hline
\end{tabular}

Diante dos resultados obtidos, destaca-se que os hidrorrepelentes poderiam resultar em maior suscetibilidade ao surgimento de manifestações patológicas pela retenção de água no revestimento base, entretanto, em fachadas, a maior quantidade de absorção de água ocorre devido a ação da chuva e os hidrorrepelentes estariam impedindo a entrada e a saturação do revestimento de argamassa e, consequentemente, não haveria ingresso de água e o revestimento permaneceria seco. Mas, se a presença de água no revestimento base se originasse a partir de componentes internos da edificação, ocorreria a dificuldade de evaporação para o meio externo resultando, possivelmente, em manifestações patológicas.

\subsection{Resistência à tração na flexão e à compressão}

Na Figura 13, apresentam-se os resultados do ensaio de resistência à tração na flexão e à compressão para as argamassas de recuperação profunda. Os revestimentos AP-IND-I1, AP-IND-I2 e AP-DO-L alcançaram as maiores resistências tanto à tração quanto à compressão e os revestimentos AP-IND-RM e AP-DO-P tiveram as menores resistências, em torno de 50\% menores que as demais argamassas. Também na Figura, apresentase a classificação atingida por cada argamassa, de acordo com a norma NBR 13281 [32]. 


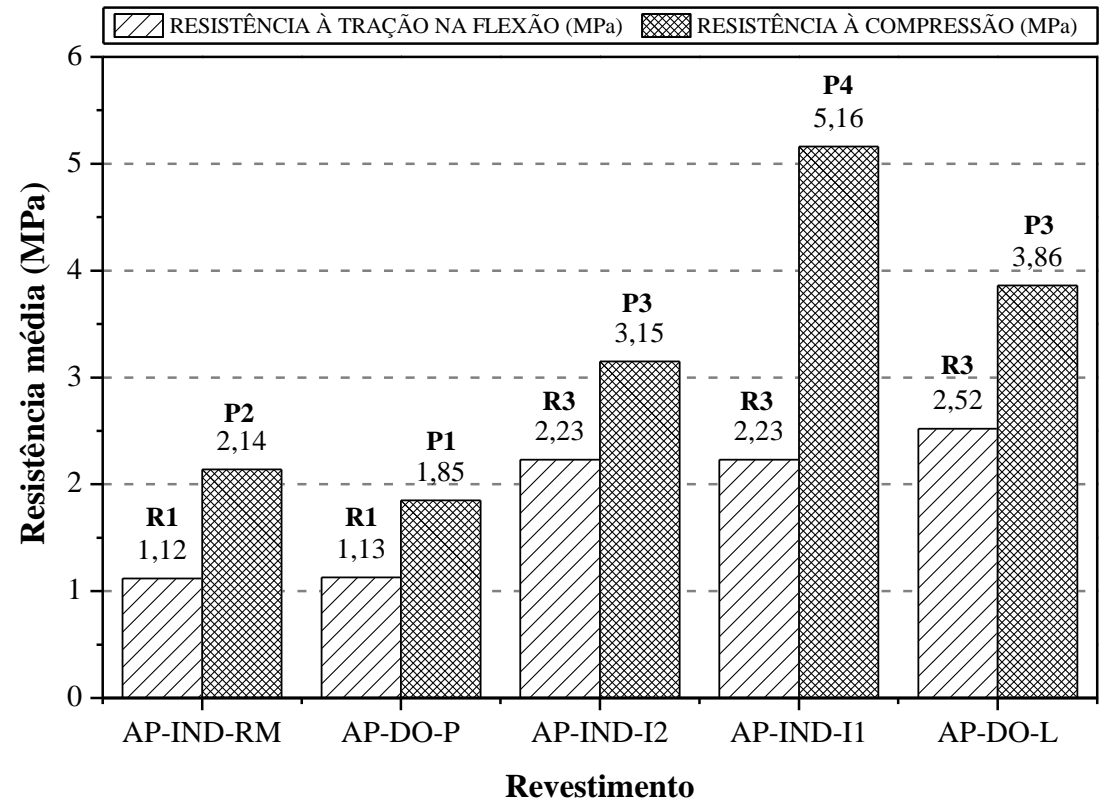

Figura 13: Resistência média à tração na flexão e à compressão das argamassas de recuperação profunda.

Apresenta-se na Tabela 13, os resultados de resistência à tração na flexão e à compressão para argamassas testadas pelos estudos citados anteriormente. Nota-se que as resistências obtidas neste trabalho ficaram mais próximas às apresentadas por Jantsch [27] que avaliou argamassas estabilizadas de 72h. Para os demais, as resistências foram mais elevadas.

Tabela 13: Resultados do ensaio de evaporação dos hidrorrepelentes.

\begin{tabular}{c|c|c|c}
\hline AUTOR & TIPO DE REVESTIMENTO DE ARGAMASSA & $\begin{array}{c}\text { RESISTÉNCIA MECÂNICA A } \\
\text { TRAÇÃO NA FLEXÃO (MPa) }\end{array}$ & $\begin{array}{c}\text { RESISTÊNCIA MECÂNICA } \\
\text { A COMPRESSÃO (MPa) }\end{array}$ \\
\hline \multirow{2}{*}{$\begin{array}{c}\text { Jantsch } \\
\text { [27] }\end{array}$} & Argamassa estabilizada de 36h & $3,68-4,91$ & $12,71-15,71$ \\
\cline { 2 - 4 } & Argamassa estabilizada de 72h & $1,23-3,02$ & $2,33-6,65$ \\
\hline $\begin{array}{c}\text { Martinho } \\
{[19]}\end{array}$ & $\begin{array}{c}\text { Argamassa com substituição da areia por } \\
\text { mistura de pellets }\end{array}$ & $3,62-6,81$ & $10,88-46,04$ \\
\hline \multirow{2}{*}{$\begin{array}{c}\text { Fonseca } \\
{[28]}\end{array}$} & Argamassa cimento:areia & 3,4 & 16,26 \\
\cline { 2 - 4 } & Argamassa cimento:areia: lama ETAR seca & $2,05-4,24$ & $7,66-17,23$ \\
\cline { 2 - 4 } & $\begin{array}{c}\text { Argamassa cimento:areia: lama ETAR calci- } \\
\text { nada }\end{array}$ & $3,95-4,87$ & $17,34-22,41$ \\
\hline
\end{tabular}

\section{CONCLUSÕES}

Este artigo avaliou o comportamento frente a estanqueidade à água de argamassas industrializadas e dosadas em obra com aditivos impermeabilizantes, e revestimentos hidrorrepelentes formadores de película possuindo como base uma argamassa industrializada sem o componente impermeabilizante.

Foi possível concluir que a permeabilidade ao vapor de água foi maior para a argamassa de recuperação profunda AP-DO-P e os demais revestimentos apresentaram menor capacidade de permitir a difusão de vapor, principalmente AP-IND-I2, AS-PB, HIDRO2 e HIDRO1. Já os hidrorrepelentes obtiveram a menor capacidade de permeabilidade ao vapor dentre todos os revestimentos avaliados.

A absorção de água por capilaridade de todos os revestimentos foi inferior à absorção capilar da argamassa de referência AP-IND-RM. Os revestimentos de argamassa de recuperação profunda AP-IND-I1 e APIND-I2 apresentaram maior estanqueidade à água. O revestimento de argamassa de recuperação superficial AS-PB foi o que mais bloqueou a penetração capilar dentre todas as argamassas. Os hidrorrepelentes reduziram em mais de 95\% a absorção capilar, sobressaindo-se o revestimento HIDRO2 seguido do HIDRO1.

Para a evaporação, o revestimento de recuperação profunda AP-IND-I2 alcançou o equilíbrio higroscópico mais rapidamente pela sua baixa absorção de água capilar, enquanto AP-IND-I1 e AP-DO-L foram mais lentas. O revestimento de argamassa AP-DO-P apresentou facilidade em atingir o equilíbrio interno e o 
revestimento de argamassa AP-IND-RM obteve alta absorção capilar, levando maior intervalo de tempo para atingir o equilíbrio higroscópico. As argamassas de recuperação superficial e os hidrorrepelentes impediram a saída da água, principalmente, a argamassa de recuperação superficial AS-PB e o hidrorrepelente HIDRO2.

Os revestimentos de argamassa de recuperação profunda AP-IND-I1, AP-IND-I2 e AP-DO-L obtiveram as maiores resistências, tanto à tração na flexão quanto à compressão. Assim, por estes revestimentos terem demonstrado boa estanqueidade à água líquida no ensaio de absorção capilar e baixa permeabilidade ao vapor de água, revela-se que, provavelmente, estas argamassas possuem menor porosidade em comparação com as demais.

Deste modo, as argamassas industrializadas de recuperação profunda AP-IND-I1 e AP-IND-I2 demonstraram melhor comportamento global, pois possuem maior controle de dosagem de seus constituintes e regulam a quantidade de água utilizada na mistura. As argamassas dosadas em obra tiveram grande influência da proporção de materiais utilizados, inclusive pela pouca informação técnica fornecida pelos fabricantes.

A argamassa de recuperação superficial AS-PB se destacou em todos os ensaios, entretanto, obteve pouca permeabilidade ao vapor de água, o que é esperado quando há alta impermeabilidade à água líquida. As argamassas colantes AS-PSP e AS-ACIII não apresentaram bons resultados diante à estanqueidade quando comparadas com os demais revestimentos.

Os hidrorrepelentes apresentaram resultados baixos em relação à estanqueidade à água, sendo que HIDRO1 e HIDRO2 foram os que mais se destacaram. Os HIDRO3 e HIDRO4 também obtiveram ótimos resultados e ainda permitiram uma permeabilidade ao vapor de água próxima ao de algumas argamassas.

Diante disso, sugere-se para a recuperação de fachadas degradadas pela umidade, o emprego de revestimentos hidrorrepelentes. Uma vez que, revelaram-se mais eficazes perante a estanqueidade à água e foram de fácil aplicação, podendo serem utilizados como última camada do sistema de revestimento de fachada.

\section{BIBLIOGRAFIA}

[1] ASSOCIAÇÃO BRASILEIRA DE NORMAS TÉCNICAS. NBR 15575-1. Edificações habitacionais Desempenho. Parte 1: Requisitos gerais. Rio de Janeiro, 2013.

[2] PALHA, F., PEREIRA, A., BRITO, J., et al., "The effect of water on the degradation of gypsum plaster coatings: inspection, diagnosis and repair", Journal of Performance of Constructed Facilities, v. 26, n. 4, 2012

[3] SALIM, N. A. A., SALLEH, N. M., ZAHAN, N. F., "Design Failure Affecting Maintenance Management on Public Higher Education Institution in Malaysia". In: The 4th International Building Control Conference, 2016, Kuala Lumpur - Malaysia. MATEC Web of Conference 66, 00122, Kuala Lumpur, 2016.

[4] DUARTE, R., FLORES-COLEN, I., BRITO, J., "In Situ Testing Techniques for Evaluation of Water Penetration in Rendered Facades - the Portable Moisture Meter and Karsten Tube". In: XII International Conference on Durability of Building Materials and Components, Porto, 2011.

[5] BALL, R. J., ALLEN, G. C., 'The measurement of water transport in porous materials using impedance spectroscopy", Journal of physics D: Applied physics, v. 43, n. 10, 2010.

[6] DELGADO, J. M. P. Q., FREITAS, V. P., GUIMARÃES, A. S., "Water movement in building walls: interfaces influence on the moisture flux", Heat Mass Transfer, v. 52, pp. 2415-2422, 2016.

[7] BAROGHEL, B.V., MAINGUY, M., LASSABATERE, T., et al., "Characterization and Identification of Equilibrium and Transfer Moisture Properties for Ordinary and high-performance Cementitious Materials", Cement and Concrete Research, v. 29, n. 8, pp. 1225-1238, ago. 1999.

[8] CHAROLA, A. E., "Salts in the deterioration of porous: an overview", Journal of the American Institute for Conservation, v. 39, pp. 327-343, 2000.

[9] ASSOCIAÇÃO BRASILEIRA DE NORMAS TÉCNICAS. NBR 9778. Argamassa e concreto endurecidos: Determinação da absorção de água por imersão - Índice de vazios e massa específica. Rio de Janeiro, 2010.

[10] FREITAS, V. P., TORRES, M. I., GUIMARÃES, A. S. Humidade Ascensional. 1 ed. FEUP Edições, 2008.

[11] BASHEER, L., KROPP, J., CLELAND, D. J. "Assessment of the durability of concrete from its permeation properties: a review”, Construction and Building Materials, v. 15, pp 93-103, 2001.

[12] YANG, F., PRADE, F., GRIFFA, M., et al., "Dark-field X-ray imaging of unsaturated water transport in 
porous materials", Applied Physics Letters, v. 105, 2014.

[13] HALL, C., YAU, M. H. R. "Water Movement in Porous Building Materials - IX. The Water Absorption and Sorptivity of Concretes", Building and Environment, v. 22, n. 1, pp 77-82, 1987.

[14] MUKHOPADHYAYA, P., BATCHELlER, D., KUMARAN, K., et al., "Correlation Between Water Vapor and Air Permeability of Building Materials: Experimental Observations", Journal of ASTM International, v. 8, n. 3, paper ID JAI102924, 2011.

[15] HALL, C., HOFF, W. D., NIXON, M. R. "Water Movement in Porous Building Materials - VI. Evaporation and Drying in Brick and Block Materials", Building and Environment, v. 19, n. 1, pp 13-20, 1984.

[16] OLIVEIRA, J. M. P.O. Estudo da durabilidade e eficácia da ação de repelentes de água em fachadas de edifícios recentes, Dissertação de Mestrado, Faculdade de Engenharia da Universidade do Porto, Portugal, 2013.

[17] PÁSCOA, L. Índice de Secagem Como Parâmetro em Serviço dos Rebocos Aplicados em Paredes Exteriores, Dissertação de Mestrado, Faculdade de Engenharia da Universidade do Porto, Portugal, 2013.

[18] GRILO, J., FARIA, P., VEIGA, R., et al., "New Natural Hydraulic Lime Mortars: physical and microstructural properties in different curing conditions", Construction and Building Materials, v. 54, p. 378-384, 2014.

[19] GONÇALVES, T. D., PEL, L., RODRIGUES, J. D. "Influence of Paints on Drying and Salt Distribution Processes in Porous Building Materials", Construction and Building Materials, v. 23, p. 1751-1759, 2009.

[20] ASSOCIAÇÃO BRASILEIRA DE NORMAS TÉCNICAS. NBR 9575. Impermeabilização - Seleção $e$ projeto. Rio de Janeiro, 2010.

[21] EUROPEAN COMMITTEE FOR STANDARDIZATION. EN 1015-19. Methods of test for mortar for masonry - Part 19: Determination of water vapour permeability of hardened rendering and plastering mortars. Bruxelas, 2004.

[22]

EUROPEAN COMMITTEE FOR STANDARDIZATION. EN 998-1. Specification for mortar for masonry - Part 1: Rendering and plastering mortar. Bruxelas, 2003.

[23] ASSOCIAÇÃO BRASILEIRA DE NORMAS TÉCNICAS. NBR 9779. Argamassa e concreto endurecidos - Determinação da absorção de água por capilaridade. Rio de Janeiro, 2005.

[24] BRITO, V. P. S., Influência dos revestimentos por pintura na secagem do suporte. Dissertação de Mestrado, Faculdade de Ciências e Tecnologia da Universidade Nova de Lisboa, Lisboa, Portugal, 2009.

[25] ASSOCIAÇÃO BRASILEIRA DE NORMAS TÉCNICAS. NBR 13279. Argamassa para assentamento e revestimento de paredes e tetos - Determinação da resistência à tração na flexão e à compressão. Rio de Janeiro, 1995.

[26] TEMP, A. L., Avaliação de revestimentos de argamassa à permeabilidade ao vapor de água, Dissertação de Mestrado, Universidade Federal de Santa Maria, RS, Brasil, 2014.

[27] JANTSCH, A. C. A., Análise do desempenho de argamassas estabilizadas submetidas a tratamento superficial com aditivos cristalizantes, Dissertação de Mestrado, Universidade Federal de Santa Maria, RS, Brasil, 2015.

[28] FONSECA, S. A. C., Estudo de argamassas com introdução de lamas de ETARS, Dissertação de Mestrado, Universidade de Coimbra, Portugal, 2018.

[29] SALOMÃO, M. C. F., BAUER, E., KAZMIERCZAK, C. S., "Drying parameters of rendering mortars", Ambiente Construído, v. 18, n. 2, pp. 7-19, abr./jun. 2018.

[30] MARTINHO, P. A. G., Análise do comportamento de argamassas com a incorporação de "pellets" de madeira, Dissertação de Mestrado, Universidade Nova de Lisboa, Portugal, 2017.

[31] FARIA, P., "Argamassas de cal e terra: características e possibilidades de aplicação", Ambiente Construído, v. 18, n. 4, pp. 49-62, out./dez. 2018.

[32] ASSOCIAÇÃO BRASILEIRA DE NORMAS TÉCNICAS. NBR 13281. Argamassa para assentamento e revestimento de paredes e tetos - Requisitos. Rio de Janeiro, 2005.

\section{ORCID}

Thiana Dias Hermann

Gihad Mohamad,

Almir Barros da Silva Santos Neto https://orcid.org/0000-0002-0615-6327

https://orcid.org/0000-0002-6380-364X

https://orcid.org/0000-0001-7306-5313 
Rogério Cattelan Antocheves de Lima https://orcid.org/0000-0001-6622-2210 André Lübeck https://orcid.org/0000-0001-5772-9933 